\title{
Direito e política internacional do meio ambiente para as áreas úmidas sul-americanas e proteção dos biomas do Pantanal brasileiro e do Chaco boliviano: desafios do diálogo das fontes e do controle de convencionalidade
}

\begin{abstract}
Valério de Oliveira Mazzuoli
Professor Associado da Universidade Federal de Mato Grosso (UFMT). Pós-doutor em

Ciências Jurídico-Políticas pela Universidade Clássica de Lisboa. Doutor em Direito Internacional pela Universidade Federal do Rio Grande do Sul (UFRGS). Mestre em Direito pela Universidade Estadual Paulista “Júlio de Mesquita Filho" (Unesp). Coordenador do Grupo de Pesquisa CNPq em Direito Internacional Público (Gedip).
\end{abstract} Advogado e consultor jurídico.

Diogo Marcelo Delben Ferreira de Lima

Doutorando em Geografia Humana pela Universidade de São Paulo (USP). Mestre em Direito Agroambiental e mestre em Geografia pela Universidade Federal de Mato Grosso (UFMT). Integrante dos Grupos de Pesquisas em Direito Internacional Público e Geografia Agrária e Conservação da Biodiversidade do Pantanal, ambos vinculados à

UFMT. Advogado.

\begin{abstract}
Sumário: 1. Introdução; 2. Metodologia; 3. O direito e a política internacional do meio ambiente aplicada às áreas úmidas sul-americanas (Sistema Ramsar e a Bacia do Prata); 4. Proteção do Pantanal brasileiro e do Chaco boliviano no âmbito do Direito Constitucional Internacional do Meio Ambiente; 5. Os desafios do diálogo das fontes e do controle de convencionalidade na efetividade da tutela ambiental; 6. Considerações finais. 7. Referências.
\end{abstract}

\section{Introdução}

No contexto do capitalismo atual e da globalização, a sociedade internacional tem experimentado grandes desafios para a promoção da dignidade humana e do bem-estar social. A atuação dos sujeitos de direito e as novas relações internacionais nos planos político e jurídico, nas diversas escalas, 
tendem a redefinir os caminhos do desenvolvimento humano e social sustentável no planeta.

$\mathrm{O}$ direito e a política internacional do meio ambiente representam o maior avanço jurídico na seara humanitária pós-Segunda Guerra Mundial, pois compreendem a ampliação qualitativa e quantitativa dos direitos humanos e importam reinterpretação dos modelos econômicos e das contradições sociais existentes.

Proveniente da tensão entre internacionalização dos direitos humanos e constitucionalização do direito internacional, a tutela ecológica impõe deveres estatais e privados em prol do equilibrio ambiental e da sadia qualidade de vida humana e animal. Dessa forma, a proteção das áreas úmidas sul-americanas e dos biomas do Pantanal brasileiro e do Chaco boliviano insere-se na questão ambiental internacional de nossos dias, isto é, na construção e na implementação dos instrumentos jurídicos e políticos adequados à conservação ambiental com respeito às atividades econômicas, sociais e culturais.

Nesse sentido, à luz do Direito Internacional das Áreas Úmidas, este ensaio pretende analisar a ressonância do Sistema Ramsar na proteção e sustentabilidade do maior ambiente úmido contínuo do planeta, situado na porção meridional da América do Sul, na região hidrográfica da Bacia do Prata (v. figura 1).

O presente estudo propõe uma abordagem jurídica baseada no direito contemporâneo, no diálogo das fontes normativas e na adoção de novos recursos jurídicos, a exemplo do controle da convencionalidade das leis.

As áreas úmidas constituem extensões de terras alagáveis marcadas pela dinâmica das águas e pela hidrografia regional, sendo, aliás, de notável heterogeneidade socioespacial em razão dos valores e práticas sociais e culturais muito diversificadas e enriquecidas pela geografia e história local. Devido à importância das áreas úmidas nos meios de vida e na manutenção dos ambientes pantaneiros e chaquenhos, cumpre, portanto, difundir estudos acadêmico-científicos indispensáveis à efetividade do direito ambiental e à governança, a exemplo do que se pretendeu realizar neste ensaio. 


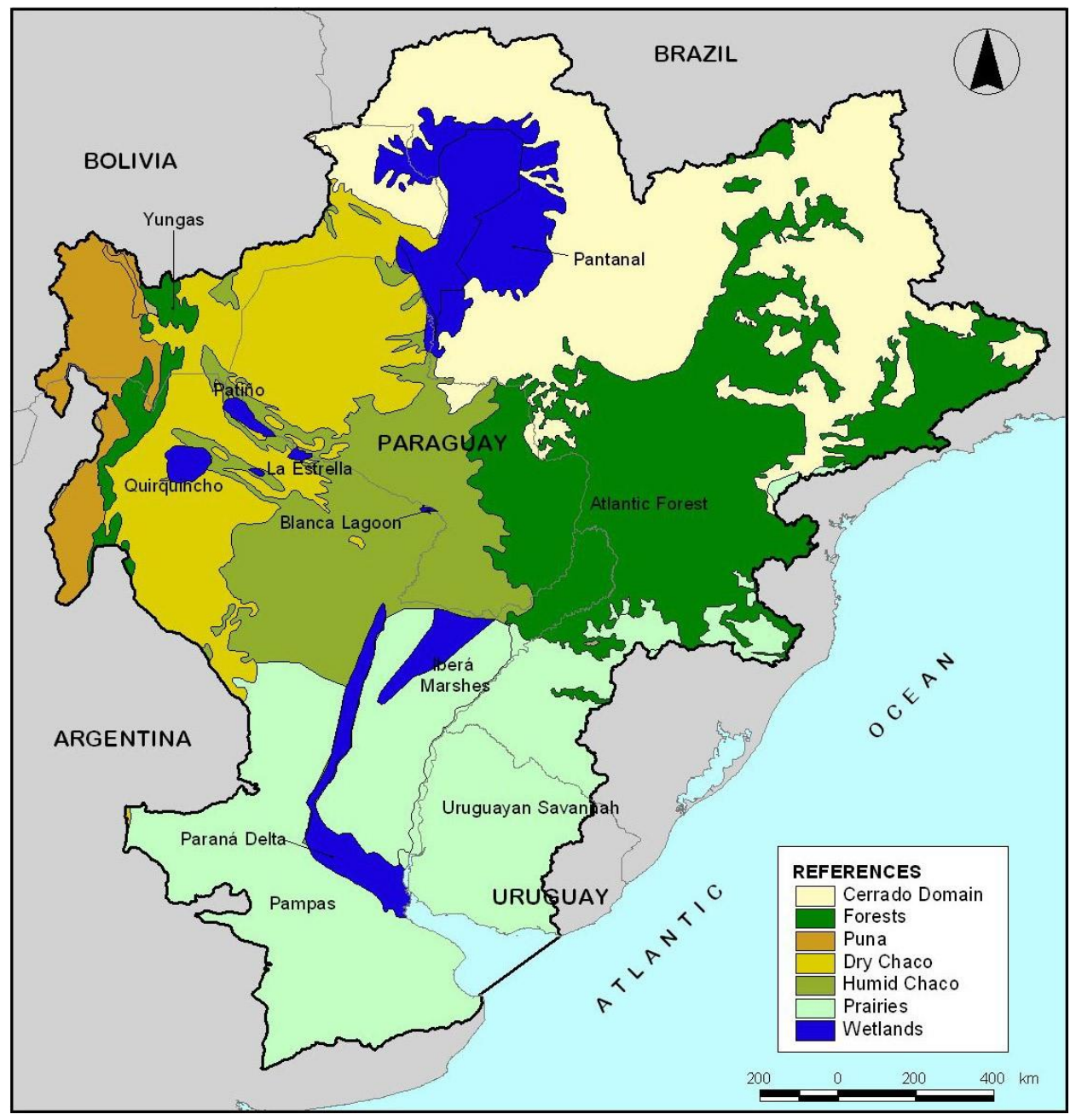

Figura 1 - Áreas úmidas na América do Sul, situadas na Bacia do Prata

Fonte: http://unesdoc.unesco.org/images/0015/001512/151252e.pdf, 138. 


\section{Metodologia}

O positivismo jurídico e a hermenêutica tradicional têm apresentado notável desgaste e manifesta incapacidade de compreender o fenômeno jurídico contemporâneo. Os fatos sociais, por si só, cada vez mais complexos e polissêmicos, inserem-se numa dinâmica rede político-institucional e normativa, exigindo enfoque teórico-metodológico crítico-reflexivo apoiado em princípios e valores da cultura jurídica pós-moderna, tais o pluralismo e a sustentabilidade.

Neste sentido, Erik Jayme faz verdadeira revolução na teoria do direito internacional com o que nominou "dialogo das fontes", vocacionado a inovar na interpretação jurídica a partir de novas técnicas de análise e resolução de antinomias ${ }^{1}$. Em outras palavras, o autor questiona a austeridade dos sistemas jurídicos (interno e internacional) e das normas, bem como as formas habituais de solução dos conflitos, notadamente o uso dos critérios hierárquico, da especialidade e cronológico. ${ }^{2}$

No entender de Claudia Lima Marques, a globalidade de direitos impõe a necessidade de se desenvolver a harmonia no ordenamento jurídico, a coordenação das normas nos sistemas jurídicos e a ampliação (com eficácia) dos direitos humanos e fundamentais ${ }^{3}$. A propósito, a ruptura de paradigmas torna possível a justiça socioambiental e promove o equilibrio nas relações jurídicas e sociais, democratizando o acesso à tutela jurisdicional e às prestações estatais relacionadas ao Estado Democrático de Direito.

Em nossa opinião, o método monista internacionalista dialógico propaga a interatividade sistêmica e normativa, a convergência do direito internacional e interno e dos respectivos arcabouços prescritivos legais em prol da proteção da pessoa humana (princípio pro homine), ao mesmo tempo em que preserva a validade formal e material das normas no plano jurídico por meio do controle de convencionalidade. ${ }^{4}$

Fato é que o "dialogismo" é recurso da tecnologia social qualificado a verificar se certa norma (ou prestação estatal) está ou não ajustada ao campo

1 JAYME, Erik. Identité culturelle et intégration: le droit international privé post-moderne. Recueil des Cours, v. 251, p. 259, 1995.

2 Para detalhes, $v$. MAZZUOLI, Valerio de Oliveira. Tratados internacionais de direitos humanos e direito interno. São Paulo: Saraiva, 2010.

3 MARQUES, Claudia Lima. O "diálogo das fontes" como método da nova teoria geral do direito: um tributo a Erick Jayme. In: MARQUES, Claudia Lima. Diálogo das fontes: dos conflitos à coordenação das normas do direito brasileiro. São Paulo. Editora Revista dos Tribunais, 2012. p. 27.

4 MAZZUOLI, Valerio de Oliveira. Curso de direito internacional público. 8. ed. rev. atual. Ampl. São Paulo: RT, 2015. p. 102. 
do Direito Internacional dos Direitos Humanos, incluindo aí todas as relações jurídicas relacionadas ao meio ambiente. Aliás, a proposta em tela busca exatamente a compreensão da totalidade da proteção dos biomas situados nas áreas úmidas sul-americanas, na Bacia do Prata, o Pantanal e o Chaco (figura 2).

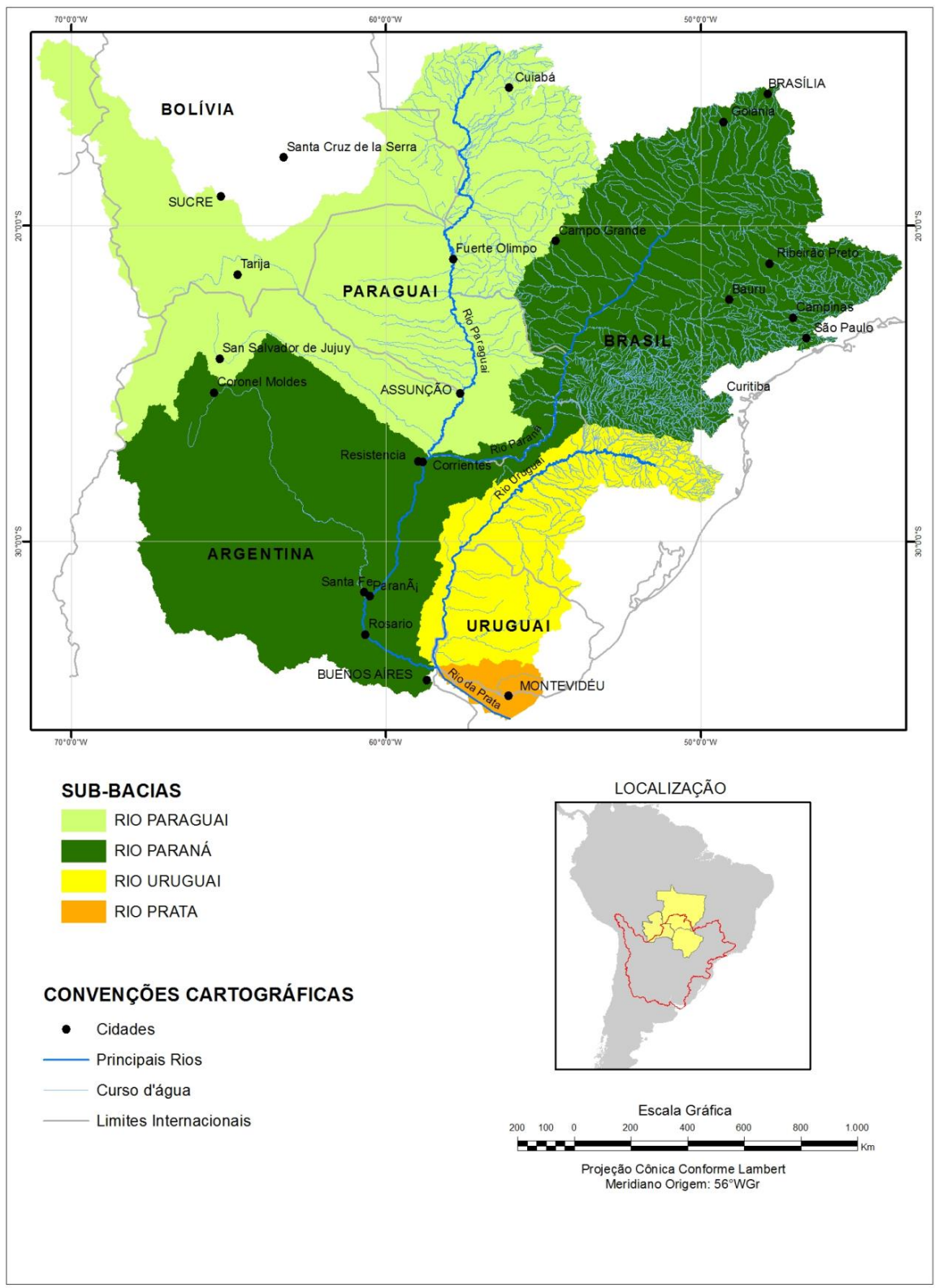

Figura 2 - Bacia do Prata e sub-bacias, com destaque para a fronteira Brasil e Bolívia Fonte: Produção técnica de Jonas Ferreira dos Santos 
A área de estudo mostra notável complexidade geográfica, primeiro, devido aos grandes rios internacionais (Paraguai, Paraná e Uruguai) e a consequente formação das zonas úmidas, segundo, em face da biodiversidade dos biomas, sobretudo do Pantanal e do Chaco, que os torna interdependentes, diferenciáveis e únicos em todo o mundo.

\section{O direito e a política internacional do meio ambiente aplicada às áreas úmidas sul-americanas (Sistema Ramsar e Bacia do Prata)}

Assim como o desenvolvimento da sociedade pressupõe a interdependência dos fatores sociais, econômicos, ambientais e culturais, a evolução do pensamento jurídico não pode prescindir da indissociabilidade das fontes materiais e formais do direito. Não se trata meramente de questão peculiar à filosofia jurídica, mas, sim, indispensável à prestação jurisdicional favorável à hermenêutica axiológica e sensivel aos contextos sociais, que faz prestigiar um sistema jurídico progressista, com arquitetura flexível e compreensível à realidade.

O Direito Internacional do Meio Ambiente - nascido da chamada crise socioambiental (deflagrada, sobretudo, após as duas Grandes Guerras) e dos desastres ambientais transfronteiriços da segunda metade do Século XX - representa o campo da ciência jurídica em que os fatos sociais (fontes materiais) e os instrumentos jurídicos (fontes formais) mostram-se amplamente interligados, confirmando a emergência de paradigma eco-humanitário pautado na ética comprometida com o desenvolvimento sustentável proveniente da dinâmica das relações internacionais, da responsabilidade compartilhada, da governança e da solidariedade intergeracional.

Os ensinamentos de Guido Soares explicitam a existência de uma "engenharia normativa ambiental" correspondente à intensificação da produção normativa destinada à tutela da natureza, dos processos ecológicos e da vida no plano internacional, com incontestes reflexos nas esferas de jurisdição doméstica. ${ }^{5}$

Em verdade, a democratização do direito internacional, isto é, a difusão de instrumentos hard law e de soft law, a exemplo de tratados internacionais e de tratados-quadros e/ou umbrella trieaties, permitiu maior alcance da norma ambiental. Por sua vez, com as conferências internacionais ambientais o tema incorporou-se à agenda dos Estados em todos os poderes e esferas (judicial, legislativa e política); prova disso é o que neste ensaio denomina-se Direito

5 SOARES, Guido Fernando Silva. A proteção internacional do meio ambiente. Barueri: Manoli, 2003. p. 1-3. 
Internacional das Áreas Úmidas Sul-Americanas, que tem como escopo a proteção dos biomas do Pantanal brasileiro e do Chaco boliviano.

Destaque-se que a rede normativa voltada à sustentabilidade dos ambientes úmidos do continente é composta pela Convenção das Zonas Úmidas de Importância Internacional (RAMSAR, 1971) e dos protocolos adicionais e recomendações provenientes das Conferências das Partes (COP), além da IV Reunião da Iniciativa Regional Ramsar da Bacia do Prata para conservação das áreas úmidas na região hidrográfica.

Em que pesem os registros históricos de tratados afetos à Bacia do Prata e outros para o uso dos cursos d'água internacionais, que forneceriam proteção reflexa aos ambientes úmidos dependentes da hidrografia regional-local e da conservação dos rios, interessa ao estudo a defesa direta e coordenada alcançada pelo Sistema Ramsar. Com efeito, a discussão sobre weatlands (áreas úmidas) objetiva o alinhamento entre os países para proteção em escala global das áreas úmidas e de seus recursos.

No âmbito das Nações Unidas, um conjunto de documentos internacionais promove a transmissão de princípios e valores jurídicos para a efetividade do direito ambiental, para resolução dos conflitos socioambientais, para redução da degradação ecológica e para maior proteção e conservação das áreas úmidas e de suas populações tradicionais.

A Convenção Ramsar, acordada em 2 de fevereiro de 1971, no Irã, atribuiu à situação jurídica das zonas úmidas a condição de tema fundamental do direito internacional público. Em vigor desde 1975, a Convenção definiu determinadas áreas no mundo, chamadas Sítios Ramsar, como integrantes da Lista Ramsar. Também, a Convenção de Ramsar teve sucesso na construção de arranjo inter e supragovernamental, com instâncias e órgãos de gestão, para a realização dos compromissos em respeito aos diversos ambientes úmidos do mundo. Com 168 Estados-membros, a Convenção tem recebido novas adesões e ampliado significativamente o seu papel na manutenção das áreas úmidas, não só o número de áreas protegidas, senão também o alcance das normas ambientais e das posturas estatais e privadas relacionadas.

O desenvolvimento do Sistema Ramsar atrela-se aos avanços obtidos nas Conferências das Partes, enquanto instância política que congrega representantes governamentais e não governamentais empenhados na efetividade da tutela ambiental e no cumprimento dos compromissos assumidos pelos Estados-contratantes, entre eles, a gestão e exploração racional das áreas úmidas, a participação social e governança ambiental, bem assim a produção do 
conhecimento cientifico. É inconteste que o tratado, que surgiu para pôr a salvo os espaços e os recursos naturais cogentes à reprodução das aves aquáticas migratórias, foi fortalecido e é considerado referência no direito internacional do meio ambiente.

Em que pese a Convenção de Ramsar ter pretendido tutelar todos os ambientes úmidos, reconhecendo e valorizando os ecossistemas locais e as funções ecológicas existentes, o certo é que ao impor que cada Estado deva estabelecer a relação dos espaços nele protegidos (lista de Sítios Ramsar), tornou-se proteção especial a tais áreas. Então, é possível depreender que há proteção jurídica direta para as áreas úmidas eleitas pela sociedade internacional, e que, de certa forma, os biomas e ecossistemas já dispõem atualmente de certa atenção normativa.

A indicação de áreas úmidas na qualidade de Sítios Ramsar é atribuição dos Estados, que têm responsabilidades na seara internacional, sobretudo de promover a execução de planos direcionados à conservação das zonas úmidas incluídas na lista e a exploração racional de outras que se encontrem nos territórios nacionais. Por certo, o número de áreas e a superfície total protegida são importantes indicadores do nível de proteção das zonas úmidas. Aliás, destacam-se na tutela desses ambientes os seguintes países: Reino Unido, México, Suécia, Espanha, Noruega, Austrália, Holanda, Argélia, França, Itália, Canadá, China, Japão, entre outros.

No tocante ao comprometimento de Brasil e Bolívia para com a Convenção de Ramsar, frise-se que tais países possuem Sítios Ramsar em seus territórios e também na região fronteiriça, o que demonstra a megadiversidade dos ambientes na região e a endogeneidade deles, isto é, cada área úmida é exuberante pelos seus próprios recursos naturais e sociais, que são singulares no conjunto da biodiversidade global.

O quadro a seguir expõe os dados referentes à adesão dos países citados, à quantidade de Sítios Ramsar no território e à área reconhecida e protegida no âmbito do Sistema Ramsar:

\begin{tabular}{l|c|c|c}
\hline País & Entrada em vigor & Número de sítios & Superfície protegida \\
\hline Brasil & 24.09 .1993 & 12 & 7.225 .687 hectares \\
\hline Bolívia & 27.10 .1990 & 11 & 14.842 .405 hectares \\
\hline
\end{tabular}

Quadro 1 - Situação jurídica de Brasil e Bolívia no âmbito da Convenção de Ramsar Fonte: Ramsar (2013) ${ }^{6}$

6 RAMSAR. The List of Wetlands of International Importance. 24 de outubro de 2013. Disponivel em: < 
De forma geral, no Brasil, os Sítios Ramsar estão dispersos em todas as regiões e biomas do país; há áreas protegidas na Amazônia, Caatinga, Mata Atlântica, Cerrado, Pantanal e Pampas. O mesmo se aplica à Bolívia, uma vez que possui Sítios Ramsar nos biomas (ou ecorregiões) da Amazônia, Cerrado, Savanas Inundáveis, nas Cordilheiras e Altiplanos.

A quantidade de Sítios Ramsar existentes no Brasil e na Bolívia é razoável, não havendo grande diferença numérica entre eles, haja vista o Brasil possuir 12 e a Bolívia ter 11 áreas incluídas na Lista Ramsar. Contudo, a Bolívia tem uma área total protegida muito superior à do Brasil, quase o dobro de hectares e, considerando o tamanho do território nacional boliviano, é de destacar o compromisso estatal com a proteção dos ambientes úmidos, e por que não dizer com as áreas protegidas de modo geral.

O quadro seguinte detalha as informações referentes ao Sítios Ramsar situados no Brasil e na Bolívia.

\begin{tabular}{|c|c|c|c|c|}
\hline País & Sítio Ramsar & Criação & UF & Área \\
\hline \multirow{12}{*}{ 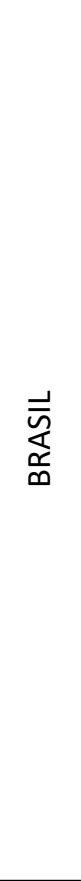 } & $\begin{array}{l}\text { Parque Nacional Marinho dos } \\
\text { Abrolhos }\end{array}$ & $02 / 02 / 10$ & Bahia & 91,300 ha \\
\hline & $\begin{array}{l}\text { Baixada Maranhense de } \\
\text { Proteção Ambiental } \\
\end{array}$ & $29 / 02 / 00$ & Maranhão & $1,775,036$ ha \\
\hline & $\begin{array}{l}\text { Parque Nacional do Cabo } \\
\text { Orange }\end{array}$ & $02 / 02 / 13$ & Amapá & 657,328 ha \\
\hline & Ilha do Bananal & $04 / 10 / 93$ & Tocantins & 562,312 ha \\
\hline & Lagoa do Peixe & $24 / 05 / 93$ & Rio Grande do Sul & 34,400 ha \\
\hline & Mamirauá & $04 / 10 / 93$ & Amazonas & $1,124,000$ ha \\
\hline & \begin{tabular}{|l|} 
Pantanal Mato-Grossense \\
\end{tabular} & $24 / 05 / 93$ & Mato Grosso & 135,000 ha \\
\hline & \begin{tabular}{|l|} 
Parque Estadual Marinho do \\
Parcel Manoel Luís
\end{tabular} & $29 / 02 / 00$ & Maranhão & 34,556 ha \\
\hline & Reentrâncias Maranhenses & $30 / 11 / 93$ & Maranhão & $2,680,911$ ha \\
\hline & \begin{tabular}{|l|} 
Reserva Particular de \\
Patrimônio Natural - Fazenda \\
Rio Negro \\
\end{tabular} & $22 / 05 / 09$ & $\begin{array}{l}\text { Mato Grosso do } \\
\text { Sul }\end{array}$ & 7,000 ha \\
\hline & $\begin{array}{|lrr|}\text { Reserva } & \text { Particular } & \text { de } \\
\text { Patrimônio } & \text { Natural } & \text { SESC } \\
\text { Pantanal } & & \\
\end{array}$ & $06 / 12 / 02$ & Mato Grosso & 87,871 ha \\
\hline & Parque Estadual do Rio Doce & $15 / 03 / 10$ & Minas Gerais & 35,973 ha \\
\hline
\end{tabular}

Continua...

http://www.ramsar.org/pdf/sitelist.pdf $>$. Acesso em: 10 nov. 13>. 


\begin{tabular}{|c|c|c|c|c|}
\hline \multirow{11}{*}{ 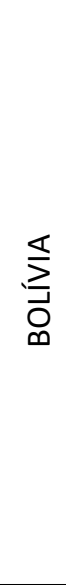 } & $\begin{array}{l}\text { Bañados del Izozog y el río } \\
\text { Parapetí }\end{array}$ & $17 / 09 / 01$ & Santa Cruz & 615,882 ha \\
\hline & Cuenca de Tajzara & $13 / 06 / 00$ & Tarija & 5,500 ha \\
\hline & Lago Titicaca (Sector Boliviano) & $26 / 08 / 98$ & La Paz & 800,000 ha \\
\hline & Lagos Poopó y Uru Uru & $11 / 07 / 02$ & Oruru & 967,607 ha \\
\hline & Laguna Concepción & $06 / 05 / 02$ & Santa Cruz & 31,124 ha \\
\hline & Los Lípez & $27 / 06 / 90$ & Potosí & $1,427,717$ ha \\
\hline & $\begin{array}{l}\text { Palmar de las Islas y las Salinas } \\
\text { de San José }\end{array}$ & $17 / 09 / 01$ & Santa Cruz & 856,754 ha \\
\hline & Pantanal Boliviano & $17 / 09 / 01$ & Santa Cruz & $3,189,888$ ha \\
\hline & Río Blanco & $02 / 02 / 13$ & Beni & $2,404,916$ ha \\
\hline & Río Matos & $02 / 02 / 13$ & Beni & $1,729,788$ ha \\
\hline & Sitio Ramsar Río Yata & $02 / 02 / 13$ & Beni & $2,813,229$ ha \\
\hline
\end{tabular}

Quadro 2 - Sítios Ramsar no Brasil e Bolívia, por ano de criação, localização e área Fonte: Ramsar (2013) ${ }^{7}$

$\mathrm{Na}$ faixa de fronteira entre Brasil e Bolívia, as áreas úmidas demonstram características socioambientais muito próprias, como os ecossistemas do Pantanal (marcados pela dinâmica das águas e armazenagem dos recursos hídricos na Bacia do Prata, formadores das áreas alagáveis prestadoras dos serviços ecológicos) e os do Chaco (menos dependentes do pulso de inundação, por isso mesmo com ambientes sub-áridos, mas com inundações periódicas e pontuais). Nessa região, merecem destaque as reservas particulares do patrimônio natural Sesc Pantanal e Fazenda Rio Nigro, nos estados de Mato Grosso e Mato Grosso do Sul, no Brasil; e o Sítio Ramsar denominado Pantanal Boliviano, no departamento de Santa Cruz, na Bolívia.

Para melhor compreensão sobre a espacialização das zonas úmidas na área de estudo, segue a ilustração cartográfica.

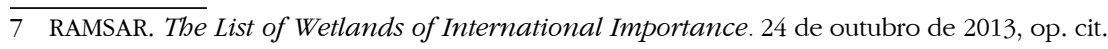




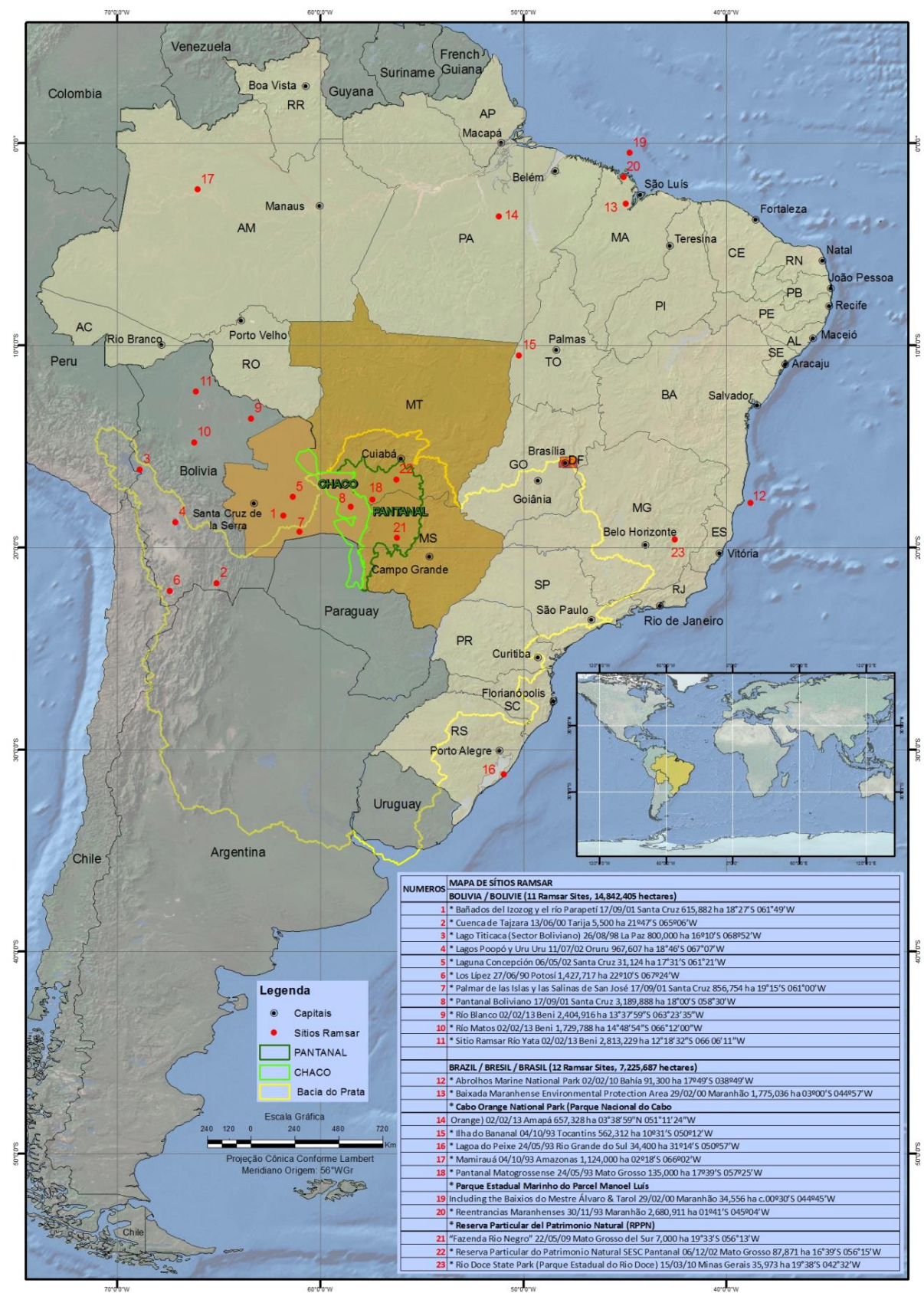

Figura 3 - Sítios Ramsar no Brasil e Bolívia, por ano de criação, localização e área. Fonte: Ramsar $(2013)^{8}$

8 RAMSAR. The List of Wetlands of International Importance. 24 de outubro de 2013, op. cit. 
Embora a continuidade territorial e a conectividade hídrica sejam notas características dos biomas do Pantanal brasileiro e do Chaco boliviano, por conseguinte, dos próprios ecossistemas e das áreas úmidas na região fronteiriça, inexistem Sítios Ramsar com esse formato jurídico. Apesar de a Convenção Ramsar prever a cooperação internacional para a gestão compartilhada das áreas úmidas fronteiriças, essa oportunidade não foi devidamente explorada pelos países referidos, ou melhor, até o ano de 2013 apenas 16 (dezesseis) sítios transnacionais foram reconhecidos no mundo, estando praticamente todos na Europa e apenas um na África.

A IV Reunião de Iniciativa Regional Ramsar, realizada em Tarija, Bolívia, em 2013, tratou da problemática referente à elaboração da estratégia para conservação e para uso sustentável de áreas úmidas na Bacia do Prata e à definição de Plano de Trabalho para a implementação de ações coordenadas entre os Sistemas Ramsar e Bacia do Prata. Certo é que um inventário das áreas úmidas sul-americanas poderia dar objetividade à gestão ambiental colaborativa em nosso continente.

A saber, a $12^{\underline{a}}$ Conferência das Partes da Convenção de Ramsar, que ocorreu em Punta Del Este, Uruguai, permitiu a discussão sobre planos estratégicos, responsabilidades das instâncias de decisão e de gestão da Convenção Ramsar, financiamento, cooperação internacional, projetos e iniciativas regionais, além de programas e ações voltados à educação, comunicação, participação, conscientização e desenvolvimento de capacidades.

A COP 12 procurou destacar as iniciativas regionais baseadas na cooperação fronteiriça, na criação de capacidades comuns, nos intercâmbios de tecnologias e de conhecimentos, bem assim na mobilização de recursos financeiros e humanos para as atividades relativas às zonas úmidas nesses territórios. Entretanto, conforme se extrai dos principais documentos de referência da conferência, com destaque para o Plano Estratégico Ramsar para 2016-2024, não houve avanços significativos na definição de áreas úmidas fronteiriças.?

Contudo, a efetividade do direito e da política internacional do meio ambiente não depende exclusivamente da imperatividade das normas vigentes, senão do conjunto de instituições transnacionais e de produção normativa que disciplinam os temas ecológicos nos planos jurídicos, o que representa a face real do emergente arranjo normativo ambiental.

9 RAMSAR. El Plan Estratégico de Ramsar para 2016-2024. Disponível em: < http://www.ramsar.org/sites/ default/files/documents/library/cop12_res02_strategic_plan_s.pdf > Acesso em: 4 set. 2016. 
Por exemplo, a Iniciativa Regional de Conservação e Uso Sustentável de Zonas Úmidas da Bacia do Prata, a partir dos diagnósticos nacionais das áreas úmidas na região, da identificação de programas e de ações sustentáveis em curso e outras a serem executadas pelo Sistema da Bacia do Prata, pode impulsionar sobremaneira a conservação dos ambientes úmidos.

Neste viés, o tratamento destinado à Bacia do Prata e a sua exploração pelos países da região remete ao regime jurídico dos rios internacionais no direito internacional ${ }^{10}$. Em que pesem a existência de vários tratados e declarações e o vasto conhecimento na área, sobretudo da doutrina internacionalista, o certo é que, na prática, essa matéria é tomada pelo casuísmo e pela aplicação direta das normas especificas.

Esse é o caso do Tratado da Bacia do Prata ${ }^{11}$, assinado por Argentina, Bolívia, Brasil, Uruguai e Paraguai no ano de 1969, em vigor desde 1970, que representa o alinhamento dos países nas questões do desenvolvimento harmônico e da integração física da Bacia do Prata e das suas áreas de influência, bem assim da exploração racional do sistema hidrológico da região para fins de navegação, utilização de água, proteção do meio ambiente, produção de conhecimento, cooperação internacional, entre outros usos. ${ }^{12}$

As relações internacionais na "fronteira úmida" são pretéritas, mas a referida convenção constitui marco regulatório na utilização compartilhada do espaço sul-americano em face da institucionalização do Sistema da Bacia do Prata. É incontroverso que a regulamentação da matéria pelo direito internacional público, devidamente apropriada pelo direito interno dos países envolvidos, contribui para harmonia e integração regional, bem como para o desenvolvimento e distribuição dos benefícios sociais e econômicos provenientes do uso das águas.

Destarte, é o Comitê Intergovernamental Coordenador dos Países da Bacia do Prata (mais conhecido como CIC Plata) o órgão permanente competente para promover, coordenar e acompanhar o andamento das ações conjuntas para o desenvolvimento da Bacia do Prata. Nessa instância de gestão e governança participam autoridades políticas e técnicas, todos os países-membros e seus respectivos representantes, que podem assumir deveres e exigir cumprimento dos compromissos assumidos.

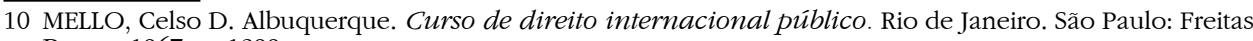
Bastos, 1967. p. 1299.

11 BRASIL. Decreto n 67.084, de 19 de agosto de 1970. Promulga o Tratado da Bacia do Prata. Publicado no D.O. 20.08.1970; BRASIL. Decreto-Lei no 682, de 15 de julho de 1969. Aprovou o tratado da Bacia do Prata, assinado em Brasilia, em 23 de abril de 1969. Publicado no D.O. 16.07.69.

12 Além de outros objetivos comuns, como: a implementação de infraestrutura física de transporte e energia, as comunicações, a complementação regional e a promoção de projetos relacionados ao aproveitamento dos recursos naturais. 
Não há dúvidas de que os Sistemas Ramsar e da Bacia do Prata, voltados à conservação das áreas úmidas e à utilização racional dos recursos hídricos da Bacia do Prata, respectivamente, se inserem numa nova sistemática internacional ambientalista; ademais, são a matéria-prima do que vem a ser o Direito Constitucional Internacional do Meio Ambiente, a fusão dos sistemas jurídicos em prol do meio ambiente e do desenvolvimento sustentável.

\section{Proteção do Pantanal brasileiro e do Chaco boliviano no âmbito do direito constitucional internacional do meio ambiente}

O constitucionalismo contemporâneo consagrou e elevou a patamar jamais visto a teoria dos direitos humanos e fundamentais. Dessa forma, as Constituições atuais caracterizam-se pela recepção da proteção dos direitos garantidos por instrumentos internacionais (tratados e declarações, $v$.g.), sobretudo aqueles afetos à dignidade da pessoa humana, bem assim pela defesa do conjunto de direitos e deveres que o cidadão-indivíduo tem em seu próprio Estado.

Isso pode ser claramente observado no Brasil, que possui um sistema jurídico bem ajustado ao direito internacional público e que põe em evidência a conformação do Estado Democrático de Direito (socioambiental).

A constitucionalização da tutela ambiental representou importante inovação no sistema jurídico e político dos países. Uma vez prestigiada na lei fundamental de determinado Estado, a proteção ao meio ambiente irradia princípios, diretrizes, regras, direitos e deveres estatais e privados sensíveis à preservação e à conservação ambiental, à defesa dos bens naturais, à promoção da qualidade de vida e da sustentabilidade em todos os seus aspectos (ecológico, econômico, social e cultural).

A norma-matriz que rege o tema nas Constituições nacionais, do Brasil e da Bolívia, está esculpida no art. 225 da Constituição da República Federativa do Brasil ${ }^{13}$ e nos arts. 33 e 34 da Constituição Política do Estado Plurinacional da Bolívia $^{14}$, enfatizando a multidimensionalidade, a indivisibilidade e a indisponibilidade do direito ambiental, além de tantos outros valores e bens jurídicos, como responsabilidade comum, desenvolvimento sustentável, compromisso intergeracional, prevenção e reparação de danos ambientais.

Tais comandos constitucionais estabelecem o direito de todos ao meio ambiente ecologicamente equilibrado e sadio para o desenvolvimento da vida

13 BRASIL. Art. 225. Constituição da República Federativa do Brasil (1988).

14 BOLÍVIA. Arts. 33 e 34. Constitución Política Del Estado de Plurinacional de Bolivia (2009). 
humana e para as futuras gerações, mas também impõem deveres ao poder público e à coletividade de proteger, conservar e restaurar o patrimônio natural, compatibilizando o seu uso com o exercício racional das atividades sociais e econômicas.

Com outras palavras, o direito constitucional do meio ambiente institui verdadeira cláusula de "prevalência do interesse público-ambiental", que reforça a implementação de posturas pró-ambiente e a observância das normas de direito vigentes.

No que se refere à atenção dada pelas cartas constitucionais à biodiversidade e aos biomas, destaca-se o art. 225, em seu $\S 4^{\circ}$, da Constituição Federal brasileira, que determina que a Floresta Amazônica, a Mata Atlântica, a Serra do Mar, o Pantanal Mato-grossense e a Zona Costeira são patrimônios nacionais, devendo sua utilização ser realizada de acordo com a lei e dentro de condições que afirmem a preservação e o uso dos recursos naturais. ${ }^{15}$

Ainda que o constituinte tenha citado expressamente biomas e ecossistemas, o rol de espaços notadamente protegidos é meramente exemplificativo, uma vez que o conjunto da biodiversidade nacional dificilmente poderia ser sintetizado na Constituição Federal. Além disso, a intenção da proteção especifica diz respeito à necessidade de leis especiais devidamente adequadas às peculiaridades dos espaços naturais (fauna, flora, hidrografia, relevo, solos, e as interações de ordem física, química e biológica $\left.{ }^{16}\right)$.

Algumas iniciativas foram tomadas para a efetividade da norma constitucional em tela, a exemplo da Lei n. ${ }^{\circ} 11.428 / 2006$, que dispõe sobre a utilização e proteção da vegetação nativa do Bioma da Mata Atlântica ${ }^{17}$, e da Lei do Estado de Mato Grosso $n^{\circ}$ 8.830/2008, que trata da política estadual de gestão e proteção da Bacia do Alto Paraguai ${ }^{18}$ e, de certo modo, do Pantanal Mato-grossense.

Enquanto isso, a Bolívia construiu sua política ambiental pautada no valor intrínseco do meio ambiente, no culto à natureza e à diversidade da vida e de sua população. A conhecida Ley Marco de la Madre Tierra y Desarrollo

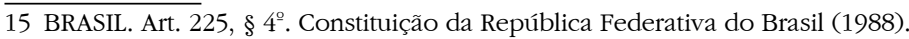

16 BRASIL. Lei n. ${ }^{\circ}$ 6.938/1981. Dispõe sobre a Política Nacional de Meio Ambiente, seus fins e mecanismos de formulação e aplicação, e dá outras providências. Art. $3^{\circ}$, I. Disponível em: < http://www.planalto.gov.br/ ccivil_03/leis/L6938.htm >. Acesso em: 4 set. 2016.

17 BRASIL. Lei n. ${ }^{\circ}$ 11.428/2006. Dispõe sobre a utilização e proteção da vegetação nativa do Bioma Mata Atlântica, e dá outras providências. Disponível em: < http://www.planalto.gov.br/ccivil_03/_ato2004-2006/2006/ lei/111428.htm >. Acesso em: 4 set. 2016.

18 MATO GROSSO. Lei n. ${ }^{\circ}$ 8.830/2008. Dispõe sobre a Política Estadual e Proteção à Bacia do Alto Paraguai no Estado de Mato Grosso e dá outras providências. Disponível em: < http://www.al.mt.gov.br/storage/ webdisco/leis/lei_4702.pdf > Acesso em: 4 set. 2016. 
Integral para Vivir Bien (Lei n. ${ }^{\circ} 301 / 2012^{19}$ ) trouxe um enfoque jurídico biocêntrico e vinculou de forma indissociável os elementos naturais e humanos, consagrando os assim chamados "direitos da natureza e do viver bem".

Sem embargo, a lei brasileira similar àquela, a Lei n. ${ }^{\circ} 6.938 / 1981^{20}$, que institui a Política Nacional de Meio Ambiente, é mais processualista e instrumental em defesa do ambiente, ao passo que a lei boliviana propõe novos contornos de entendimento que poderão avançar caso sejam prestigiadas as normas de direito internacional público.

O nível de abertura da ordem jurídica de um Estado depende sobremaneira das normas constitucionais relacionadas aos princípios fundamentais, aos direitos e às garantias de seus cidadãos, à organização político-administrativa, à política externa e às relações internacionais. Porém, é notório que há certa complexidade para a recepção dos instrumentos jurídicos e das normas de direito internacional público apresentados nas Constituições.

Ainda que nas Constituições do Brasil e da Bolívia exista um rol de dispositivos virtualmente interligados que expressam a abertura de sua ordem jurídica, o certo é que nesses dois países a incorporação do direito internacional ao direito interno ainda é complexa e morosa, especialmente no âmbito parlamentar.

No caso brasileiro, os dispositivos constitucionais de maior importância no âmbito dessa temática são: art. $4^{\circ}$, e seus incisos e parágrafo único; o art. $5^{\circ}$, $\S \S$ $1^{\circ}, 2^{\circ}, 3^{\circ}, 4^{\circ} ;$ art. 49, I; art. 84, VIII ${ }^{21}$. Já no caso boliviano, vale destacar: arts. 13 ao 20 , e arts. 255 ao $260^{22}$. De modo geral, as regras de direito constitucional versam sobre o "direito dos tratados" e também dispõem sobre as etapas, os requisitos e as condições para a celebração de tratados e instrumentos internacionais.

Com efeito, o direito constitucional positivo disciplina a forma de incorporação dos instrumentos e das normas internacionais, e não só o procedimento a ser adotado para a vigência e validade das normas internacionais, mas o status jurídico, se elas possuem força supraconstitucional, se equivalem às normas constitucionais, ou se enquadram nos níveis infraconstitucional, supralegal ou legal.

19 BOLÍVIA. Ley 301. Ley de 15 de octubre de 2012. Ley Marco de Madre Tierra Y Desarrollo Integral Para Vivir Bien. Gaceta Oficial de Bolivia. Disponível em: <http://www.planificacion.gob.bo>. Acesso em: 15 set. 13.

20 BRASIL. Lei n. ${ }^{\circ} 6.938 / 1981$, op. cit.

21 BRASIL. Art. $5^{\circ}, \S \S 1^{\circ}, 2^{\circ}, 3^{\circ}, 4^{\circ}$; art. 49, I; art. 84, VIII. Constituição da República Federativa do Brasil (1988).

22 BOLÍVIA. Arts. 13 ao 20, e arts. 255 ao 260. Constitución Política Del Estado de Plurinacional de Bolivia (2009). 
A polêmica em torno da tensão existente entre direito internacional e direito interno contribui para discussão sobre a hierarquia das normas internacionais, para uma fadiga teórica que só faz revitalizar conceitos positivistas e formalistas ultrapassados da teoria pura do direito.

Um novo método, portanto, há de ser levado em consideração quando se pensa na incorporação (e posterior interpretação) das normas internacionais de direitos humanos ao direito interno; dois deles são o "diálogo das fontes" e o controle de convencionalidade.

\section{Desafios do diálogo das fontes e do controle de convencionalidade na efetividade da tutela ambiental}

A atualidade do debate se atribui à importância dada à questão dos direitos humanos na sociedade internacional. Ainda, porém, que se possa justificar a defesa da tese da hierarquia das normas internacionais quando estas forem referentes a temas gerais do direito, o certo é que esse entendimento jamais poderá ser levado a cabo no que tange aos temas relativos à proteção dos direitos humanos.

De fato, a prevalência dos direitos humanos pressupõe a aplicação da norma mais favorável à pessoa humana, independentemente da tipologia do instrumento jurídico em que se encontra. Ocorre que o direito constitucional fixa alguns obstáculos à melhor interpretação jurídica.

No Brasil, a reforma constitucional, via Emenda $n^{\circ} 45 / 2004^{23}$, atualizou as questões de direito internacional e renovou as polêmicas afetas à abertura da ordem jurídica interna e ao respeito aos direitos humanos. $O$ art. $5^{\circ}, \S 2^{\circ}$, da Constituição Federal de $1988^{24}$, se mostra determinante na interpretação jurídica atual, pois funda a pedra angular da abertura constitucional da ordem jurídica brasileira ao abrigar a chamada "cláusula de não exclusão" de direitos, segundo a qual os direitos e as garantias previstos na Carta não excluem outros decorrentes dos tratados internacionais de direitos humanos em que a República Federativa do Brasil seja parte.

Contudo, a interpretação sistemática dos dispositivos constitucionais provoca dúvidas e questionamentos que são importantes, mas, à luz do direito

23 BRASIL. Emenda Constitucional n. ${ }^{\circ}$ 45/2004. Altera dispositivos dos arts. 5ํ, 36, 52, 92, 93, 95, 98, 99, 102, 103, 104, 105, 107, 109, 111, 112, 114, 115, 125, 126, 127, 128, 129, 134 e 168 da Constituição Federal, e acrescenta os arts. 103-A, 103B, 111-A e 130-A, e dá outras providências. Disponível em: < http://www.planalto.gov.br/ ccivil_03/Constituicao/Emendas/Emc/emc45.htm >. Acesso em: 7 set. 2016.

24 BRASIL. Art. 5,$\S 2^{\circ}$, da Constituição da República Federativa do Brasil (1988). 
internacional público, foram superados pela doutrina jus publicista qualificada. $\mathrm{O}$ art. $5^{\circ}, \S 3^{\circ}$, da Constituição Federal ${ }^{25}$, define procedimento específico para aprovação de tratados internacionais envolvendo direitos humanos (necessidade de aprovação do Congresso Nacional, nas duas Casas, em dois turnos, por maioria qualificada de três quintos).

Numa primeira análise, a norma constitucional deu o mesmo tratamento das emendas constitucionais aos tratados internacionais, já que o procedimento jurídico-legislativo para a aprovação de ambos é o mesmo (arts. $5^{\circ}, \S 3^{\circ}$, e 60 , da $\mathrm{CF} / 1988)^{26}$. Todavia, as normas definidoras de direitos e garantias fundamentais têm aplicação imediata - ordem constitucional proveniente do art. $5^{\circ}$, $\S 1^{\circ}$, da Constituição $\mathrm{Federal}^{27}$, que relativiza a importância da processualística prevista para aprovação e incorporação de tratados.

Parafraseando Antonio Augusto Cançado Trindade, o direito constitucional brasileiro não pode negligenciar os avanços jurídicos conquistados nas últimas décadas no âmbito do Direito das Gentes, que consagrou a primazia dos direitos humanos ${ }^{28}$. É o direito internacional público, por meio do conjunto das fontes formais, sobretudo da Convenção de Viena sobre o Direito dos Tratados de 1969, que determina regras claras para celebração dos tratados e para a vigência e validade das normas internacionais.

Se bem que a jurisprudência nacional tem encontrado dificuldades para apresentar um entendimento consistente e uníssono no sentido de reconhecer a aplicação imediata das normas de direitos humanos e fundamentais, o que tem se observado é a pluralidade de decisões judiciais comprometidas com a causa, com distintos fundamentos e níveis de compreensão jurídica.

Não se trata aqui de subestimar o direito constitucional positivo, mas, sim, de renová-lo com os princípios e os valores da ordem jurídica internacional democrática e progressista.

A Bolívia enfrenta o desafio similar de consolidar uma hermenêutica constitucional que prestigie o diálogo das fontes, a interação dos instrumentos jurídicos internacionais e nacionais em benefício da pessoa humana, da efetividade e da eficácia dos direitos humanos e fundamentais. No caso boliviano, as normas constitucionais são mais diretas e taxativas, estando o texto de sua

$\overline{25 \text { BRASIL. Art. } 5^{\circ}}$, $\S 3^{\circ}$, da Constituição da República Federativa do Brasil (1988).

26 BRASIL. Art. 60 da Constituição da República Federativa do Brasil (1988).

27 BRASIL. Art. $5^{\circ}, \S 1^{\circ}$, da Constituição da República Federativa do Brasil (1988).

28 TRINDADE, Antonio Augusto Cançado. Direitos humanos e meio ambiente: paralelo dos sistemas de proteção internacional. Porto Alegre: Sérgio Antonio Fabris, 1993. p. 113-117. 
Constituição repleto de comandos jurídicos que tornam possível a abertura material da ordem jurídica do Estado.

De fato, o art. 13, IV, da Constituição boliviana ${ }^{29}$, sustenta que os tratados e as convenções internacionais, aprovados pela Assembleia Nacional Constituinte, que reconhecem os direitos humanos, prevalecem na ordem interna, e que os direitos e deveres previstos na Constituição devem ser interpretados conforme os tratados internacionais de direitos humanos ratificados pelo Estado.

Ainda nesse tema, os arts. 256 e 257, ambos da Constituição boliviana ${ }^{30}$, asseguram que quando os tratados e instrumentos internacionais em matéria de direitos humanos forem mais benéficos, a aplicação destes será preferencial e a interpretação dos direitos fundamentais será feita de acordo com aqueles; impõem ainda que os tratados internacionais (gerais) ratificados integram o ordenamento jurídico boliviano com força de lei. Assim, a dogmática constitucional procura preservar a supremacia dos direitos humanos e uma ordem jurídica flexível na aplicação de princípios e normas fundamentais.

Tal como ocorre no sistema jurídico brasileiro ${ }^{31}$, o procedimento boliviano para a celebração e execução de tratados internacionais envolve uma sequência de atos complexos, tanto políicos quanto jurídicos, os quais, de certa forma, emprestam legitimidade e autoridade normativa para os tratados e outros instrumentos internacionais.

Pelo fato, porém, de não se admitir a submissão dos direitos humanos às soberanias nacionais (Estado) nem aos poderes instituídos (Executivo, Legislativo e Executivo), não merecem prosperar normas e entendimentos jurisprudenciais ou doutrinários que reneguem a imperatividade do direito internacional dos direitos humanos. Atualmente, a hermenêutica jurídica não pode prescindir de abordagem teórico-metodológica fundada no diálogo das fontes e no controle de convencionalidade das normas.

É atribuição do operador do direito (e do cidadão) e dever de todas as instituições do Estado (legislativas, executivas e judiciárias) orientar-se pela correta aplicação da lei e da norma e pelo apreço ao ordenamento jurídico uno e indivisível. Cumpre ao intérprete do direito realizar habitualmente a verificação de vigência e validade das normas, e deve assim proceder operacionalizando o controle de convencionalidade das normas, se estas estão ou não de acordo com o conjunto normativo mais benéfico existente.

\footnotetext{
29 BOLÍVIA. Art. 13, IV, Constitución Política Del Estado de Plurinacional de Bolivia (2009). 30 BOLÍVIA. Arts. 256 e 257. Constitución Política Del Estado de Plurinacional de Bolivia (2009).

31 Para estudos aprofundados sobre o tema, v. MAZZUOLI, Valerio de Oliveira. Direito dos tratados. 2. ed. rev., atual. e ampl. Rio de Janeiro: Forense, 2014.
} 
O controle de convencionalidade proporciona o exame de conformidade das normas domésticas com os tratados internacionais de direitos humanos, não sendo mais suficiente (doravante) apenas a simples análise de constitucionalidade das leis, isto é, se a norma está apta ou não a integrar o bloco de constitucionalidade; agora, para que a norma interna seja válida, deve estar de acordo com a Constituição e com os tratados internacionais de direitos humanos em vigor no Estado. ${ }^{32}$

Logo, se apresentar dupla conformidade a norma será vigente e válida; se, contudo, for contrária aos tratados de direitos humanos será vigente, mas inválida (ainda que esteja de acordo com o direito constitucional). ${ }^{33}$

Doravante, validade e vigência não se confundem. A capacidade de determinada norma para produzir os efeitos jurídicos e sociais esperados diz respeito ao aspecto de sua validade - adequação ao direito constitucional internacional. Enquanto isso, a vigência refere-se aos trâmites formais de elaboração e aprovação dos atos normativos, à mera existência da norma e sua conformidade com o processo legislativo previsto na Constituição. ${ }^{34}$

Com o diálogo das fontes, é então possível desenvolver hermenêutica acertada para resolução das aparentes antinomias e dos conflitos de direitos humanos e fundamentais, uma vez que se busca, invariavelmente, a aplicação da norma mais favorável à proteção da pessoa humana (princípio pro bomine) na seara humanitária e ao mais alto nível de tutela ambiental (princípio pro natura) na seara ecológica.

Além do mais, nas duas áreas citadas deverá ser observado o princípio do não retrocesso ou da proibição de regresso, ou seja, de não redução dos direitos humanos e fundamentais garantidos nos instrumentos jurídicos nacionais e internacionais.

Com o controle de convencionalidade, ainda que determinada norma esteja vigente, isto é, exista formalmente no direito constitucional positivo e até no direito internacional, se admite a verificação da compatibilidade com os direitos humanos e o reconhecimento de validade (ou invalidade) e de exigibilidade da referida norma. O recurso de tecnologia social em questão é verdadeiro instrumento jurídico de proteção do indivíduo e da sociedade internacional

32 Cf. FERRAJOLI, Luigi. Derechos y garantías: la ley del más débil. Trad. Perfecto Andrés Ibáñez e Andrea Greppi. Madrid: Trotta, 1999. p. 15-34.

33 MAZZUOLI, Valerio de Oliveira. O controle jurisdicional da convencionalidade das leis. 2. ed. rev. atual. ampl. São Paulo: Revista dos Tribunais, 2011. p. 73-154.

34 Cf. FERRAJOLI, Luigi, op. cit., p. 20-22. 
contra a impertinente liberalidade peculiar aos Estados e à imprevisibilidade das posturas e ações das instituições públicas.

Os axiomas apresentados aplicam-se indistintamente a todos os casos que envolvam os direitos humanos (incluindo aí os direitos ambientais). A partir daquelas premissas, não é difícil compreender que os instrumentos jurídicos (internacionais e domésticos) como os tratados internacionais inseridos no Sistema Ramsar e no Sistema da Bacia do Prata (e o direito constitucional ambiental do Brasil e da Bolívia) se complementam na proteção do meio ambiente e das áreas úmidas, aliás, é exatamente isso que o diálogo das fontes visa promover: a coexistência harmônica entre as diversas fontes do direito.

Essa forma de apreensão do fenômeno jurídico repulsa o dogmatismo e o formalismo, responsáveis por prática jurídica descontextualizada e lesiva à integridade dos direitos humanos e fundamentais. Não sendo mais concebíveis essas fórmulas e experimentos na interpretação da realidade social, a transformação do direito pressupõe metodologia jurídica sensível aos princípios basilares de proteção da pessoa humana e técnicas que permitam a vigilância constante das normas, como é o controle de convencionalidade, que pretende ser a garantia jurídica em favor da sociedade internacional e das normas convencionais mais benéficas.

Neste estudo a respeito da tutela das áreas úmidas o controle de convencionalidade é reconhecido como recurso competente para obstar inovações artificiosas que possam vir a reduzir a proteção dos direitos humanos e fundamentais das comunidades políticas viventes na região e a afetar negativamente a conservação dos ambientes úmidos do Pantanal brasileiro e do Chaco boliviano.

Em tempos de crise e de instabilidade política e social, a garantia do não retrocesso põe a salvo o cidadão enquanto pessoa humana, a vida e o meio ambiente para as presentes e futuras gerações.

\section{Considerações finais}

A crise socioambiental contribuiu para que o direito e a política internacional do meio ambiente se tornassem mais dinâmicos. Reflexo disso é a nova engenharia normativa que defende uma arquitetura flexível de princípios e regras jurídicas para a defesa do meio ambiente e para a sustentabilidade. $O$ conjunto de instrumentos jurídicos (internacionais e nacionais) serve para dar efetividade à tutela ambiental; os tratados internacionais, as Constituições nacionais e todo o arcabouço normativo fazem parte do ordenamento jurídico "cosmopolita", típico da pós-modernidade pela qual passa o mundo atual. 
A Convenção de Ramsar é fundamental para a conservação dos ambientes úmidos em todo o mundo, e nos biomas do Pantanal brasileiro e do Chaco boliviano. O desenvolvimento institucional e normativo do Sistema Ramsar tem ampliado significativamente o alcance da proteção das áreas úmidas (e não só aquelas incluídas na Lista Ramsar) e promovido o respeito às comunidades tradicionais viventes nesses ecossistemas.

Nessa perspectiva, a Iniciativa Regional de Conservação e Uso Sustentável de Zonas Úmidas da Bacia do Prata pretende integrar as ações pró-ambiente e avançar na sustentabilidade regional.

O Direito Constitucional Internacional do Meio Ambiente, como demonstrado à luz das ordens jurídicas brasileira e boliviana, compreende as normas constitucionais de proteção ambiental e de celebração e incorporação de tratados e outros instrumentos internacionais de proteção, indispensáveis à abertura constitucional e à efetividade dos direitos humanos e fundamentais.

Apesar disso, tanto o Brasil quanto a Bolívia fornecem tratamento jurídico especifico ao meio ambiente, à natureza (Bolívia), aos biomas (Brasil) e às áreas úmidas, inclusive ambos possuem Sítios Ramsar na relação de áreas úmidas protegidas no mundo.

A pós-modernidade e a transformação do direito estão a exigir novas posturas político-jurídicas e a ruptura de paradigmas na sociedade internacional. O monismo internacionalista dialógico e o surgimento de nova abordagem teórico-metodológica na ciência jurídica, apoiada no diálogo das fontes e no controle de convencionalidade, prometem revolucionar a hermenêutica e a prática jurídica e inovar positivamente na interpretação e aplicação da norma.

Cabe, contudo, ao intérprete da lei (em sentido amplo) prestigiar os princípios e valores jurídicos da dignidade da pessoa humana (princípio pro bomine) e do melhor nível de proteção ambiental (princípio pro nature).

Os desafios para a efetividade do direito ambiental e para eficácia dos direitos humanos e fundamentais só podem ser superados no bojo do novo arranjo normativo ambiental e com o desenvolvimento institucional e jurídico em prol da integridade do meio ambiente e da pessoa humana, com os compromissos e responsabilidades do Estado e da sociedade. 


\section{Referências}

COMITÊ INTERGOVERNAMENTAL COORDENADOR DOS PÁISES DA BACIA DO PRATA. Programa para a Gestão Sustentável dos Recursos Hídricos da Bacia do Prata, considerando os efeitos decorrentes da variabilidade e mudança do clima. CIC PLATA, março de 2012. Disponível em: < http://www.cicplata.org/documents/08122011/Cuenca Portugues.pdf. > Acesso em: 10 nov. 2013.

FERRAJOLI, Luigi. Derechos y garantías: la ley del más débil. Trad. Perfecto Andrés Ibáñez e Andrea Greppi. Madrid: Trotta, 1999.

JAYME, Erik. Identité culturelle et intégration: le droit international privé post-moderne. Recueil des Cours, v. 251, p. 9-267, 1995.

LIMA, Diogo Marcelo Delben Ferreira de Lima. Tutela internacional das áreas úmidas sul-americanas: instrumentos de proteção do Pantanal e do Chaco. 2012. Dissertação (Mestrado em Direito Agroambiental)- Instituto de Ciências Humanas e Sociais, Universidade Federal de Mato Grosso, Cuiabá, 2012.

MARQUES, Claudia Lima. O "diálogo das fontes" como método da nova teoria geral do direito: um tributo a Erick Jayme. In: MARQUES, Claudia Lima. Diálogo das fontes: dos conflitos à coordenação das normas do direito brasileiro. São Paulo. Editora Revista dos Tribunais, 2012.

MAZZUOLI, Valerio de Oliveira. O controle jurisdicional da convencionalidade das leis. 2 ed. rev. atual. ampl. São Paulo: Revista dos Tribunais, 2011.

. Curso de Direito Internacional Público. 8 ed. rev. atual. Ampl. São Paulo: RT, 2015.

. Direito dos tratados. 2. ed. rev., atual. e ampl. Rio de Janeiro: Forense, 2015.

. Tratados internacionais de direitos humanos e direito interno. São Paulo: Saraiva, 2010.

MELLO, Celso D. Albuquerque. Curso de direito internacional público. Rio de Janeiro. São Paulo: Freitas Bastos, 1967.

RAMSAR. The List of Wetlands of International Importance. 24 de outubro de 2013. Disponivel em: < http://www.ramsar.org/pdf/sitelist.pdf.> Acesso em: 10 nov. 13.

. El Plan Estratégico de Ramsarpara 2016-2024. Disponível em: < http://www.ramsar.org/ sites/default/files/documents/library/cop12 res02_strategic_plan_s.pdf. > Acesso em: 4 set. 2016.

SOARES, Guido Fernando Silva. A proteção internacional do meio ambiente. Barueri: Manoli, 2003.

TRINDADE, Antonio Augusto Cançado. Tratado de direito internacional dos direitos humanos. Porto Alegre: Sérgio Antonio Fabris, 2003.

Direitos humanos e meio ambiente: paralelo dos sistemas de proteção internacional.

Porto Alegre: Sérgio Antonio Fabris, 1993. 